\title{
Improved T1 fitting with the MOLLI sequence
} \author{
Jonathan W Weinsaft ${ }^{3}$, Yi Wang ${ }^{2,1}$ \\ From 16th Annual SCMR Scientific Sessions \\ San Francisco, CA, USA. 31 January - 3 February 2013
}

Mitchell A Cooper ${ }^{2,1^{*}}$, Thanh Nguyen ${ }^{1}$, Pascal Spincemaille ${ }^{1}$, Jonathan D Kochav ${ }^{4}$, Martin R Prince ${ }^{1}$,

\section{Background}

T1 mapping has great potential for diagnosing diffuse cardiomyopathies. Modified Look Locker Inversion Recovery (MOLLI) is a promising 2D SSFP technique to measure T1 differences between healthy and diseased states in cardiac tissue. However, this method has been found to provide variable $\mathrm{T} 1$ values at different flip angles. Here we develop an improved fitting algorithm which accounts for the imperfect RF flip angle profile and SSFP signal evolution in MOLLI. We show that significantly improved T1 accuracy can be achieved across a larger range of flip angle in human calf muscle. This algorithm is then applied to MOLLI data obtained in the heart using an optimized flip angle.

\section{Methods}

Imaging experiments were performed at $1.5 \mathrm{~T}$. For calf muscle $(\mathrm{n}=3)$, the MOLLI sequence was implemented with

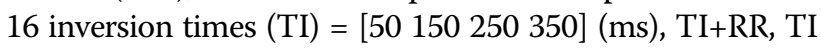
$+2 * R R, T I+3 * R R$, where $R R=750 \mathrm{~ms}$ is the R-R interval of the simulated cardiac gating (chosen intentionally to eliminate the effect of variable RR on the $\mathrm{T} 1$ accuracy). Three flip angles of $30^{\circ}, 60^{\circ}$ and $90^{\circ}$ were used. MOLLI data fitting was performed using the original formula ( $\mathrm{T} 1=$ $\mathrm{T} 1 *$ (B/A-1), where $\mathrm{T} 1 *$, A and $\mathrm{B}$ are obtained by a threeparameter exponential fit) as well as the proposed algorithm. The gold standard inversion recovery spin echo (IR$\mathrm{SE})$ sequence was used to obtain reference T1 values.

Cardiac T1 mapping was then performed $(n=5)$ using a $90^{\circ}$ flip angle (determined to be optimal from the calf muscle experiment). 16 TI were acquired, however there was no free relaxation between Look Locker epochs in order to shorten scan time.

\section{Results}

Table 1 compares in vivo calf muscle $\mathrm{T} 1$ values obtained with the original and proposed algorithms. While the original method provided highly variable T1's and larger residuals at higher flip angles (up to $14.9 \%$ ), the proposed method provided accurate $\mathrm{T} 1$ and consistently low fitting residuals (1-2\%) over all flip angles with minimal $\mathrm{T} 1$ error at $90^{\circ}$.

Figure 1 shows a representative cardiac short-axis T1 map for one volunteer. The myocardial T1 averaged over 5 volunteers was $986 \pm 45 \mathrm{~ms}$.

\section{Conclusions}

While MOLLI allows for fast probing of tissue T1, the original fitting formula does not account for the effect of an imperfect RF excitation profile and only provides an approximation to the true SSFP signal evolution. Our improved fitting method can provide more accurate $\mathrm{T} 1$ results by incorporating these effects in the signal fitting.

\section{Funding}

NSFGRFP; Grant number: DGE-0707428;

NIH; Grant number: HL064647.

Table 1

\begin{tabular}{|c|c|c|c|c|c|}
\hline \multirow[t]{2}{*}{ Flip angle } & \multicolumn{3}{|c|}{ T1 (ms) } & \multicolumn{2}{|c|}{ Fitting residual (\%) } \\
\hline & IR-SE & MOLLI & Proposed & MOLLI & Proposed \\
\hline $30^{\circ}$ & & 927 & 955 & 6.0 & 1.9 \\
\hline $60^{\circ}$ & 980 & 969 & 969 & 12.1 & 1.1 \\
\hline $90^{\circ}$ & & 1032 & 978 & 14.9 & 1.1 \\
\hline
\end{tabular}

${ }^{2}$ BME, Cornell University, Ithaca, NY, USA

Full list of author information is available at the end of the article

(c) 2013 Cooper et al; licensee BioMed Central Ltd. This is an Open Access article distributed under the terms of the Creative Commons 


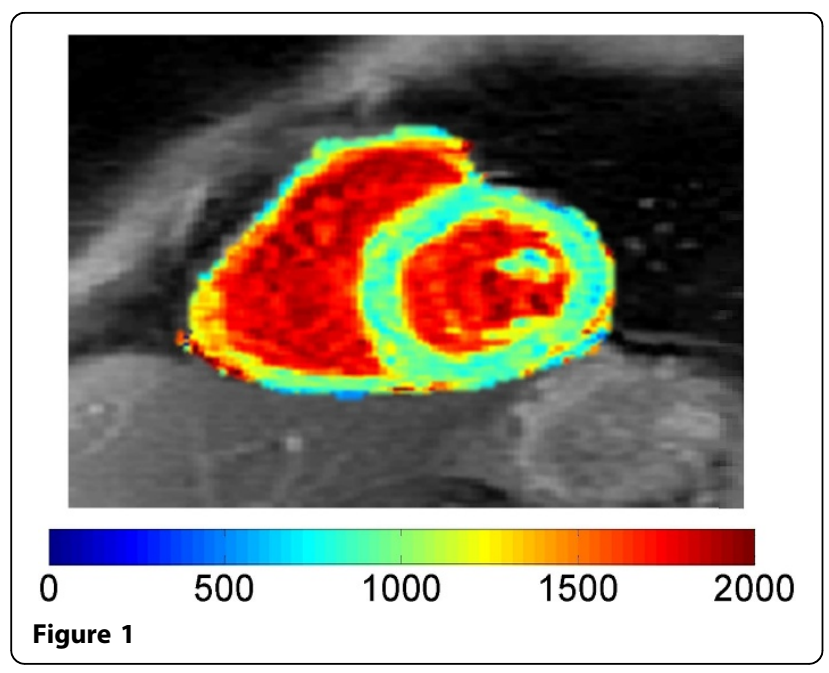

Author details

${ }^{1}$ Radiology, Weill Cornell Medical College, New York, NY, USA. ${ }^{2}$ BME, Cornell University, Ithaca, NY, USA. ${ }^{3}$ Cardiology, Weill Cornell Medical College, New York, NY, USA. ${ }^{4}$ School of Medicine, Duke University, Durham, NC, USA.

Published: 30 January 2013

doi:10.1186/1532-429X-15-S1-P50

Cite this article as: Cooper et al:: Improved T1 fitting with the MOLLI

sequence. Journal of Cardiovascular Magnetic Resonance 2013

15(Suppl 1):P50.
Submit your next manuscript to BioMed Central and take full advantage of:

- Convenient online submission

- Thorough peer review

- No space constraints or color figure charges

- Immediate publication on acceptance

- Inclusion in PubMed, CAS, Scopus and Google Scholar

- Research which is freely available for redistribution

Submit your manuscript at www.biomedcentral.com/submit
C Biomed Central 